\title{
Genetic Algorithm for the Multi-objective Optimization of Product Gene
}

$$
\text { Qingsong } \mathrm{Ai}^{1,2, \mathrm{a}} \text {, Zhou Liu }{ }^{1,2, \mathrm{~b}} \text {, Yan Wang }{ }^{1,2, \mathrm{c}}
$$

${ }^{1} S c h o o l$ of Information Engineering, Wuhan University of Technology, 430070, Wuhan, China

\author{
${ }^{2}$ Key Lab. of Fiber Optic Sensing Technology and Information Processing, 430070, Wuhan, China \\ aqingsongai@whtu.edu.cn, bliuzhoujoe@163.com, wywhut@163.com
}

Keywords: Product gene; Multi-objective optimization; Modified genetic algorithm

\begin{abstract}
In order to adapt to the rapid development of the manufacturing industry, product genetic engineering arises at the historic moment. Finding the optimal solution under more than one decision variables of the solution set is becoming the most important problems that we should solve. In this paper, we proposed a modified genetic algorithm to solve gene product genetic engineering of multi-objective optimization problems. The new concepts such as matrix encoding, column crossover and adaptive mutation are proposed as well. Experimental results show that the modified genetic algorithm can find the optimal solutions and match the customer's expectations in modern manufacture.
\end{abstract}

\section{Introduction}

In the current economic globalization and changing market environment, the modern manufacturing enterprises focus on how to meet the demand of the market and develop products that satisfy the customers better and faster. People applied natural law to manufacture, so they put forward the concept of the product gene model. In recent years, the product model and related information modeling technology research has been very active, such as F.B. Zhu from Taiwan put forward Chinese characters and Chinese characters engineering [1], Gero put forward the design of genetic engineering [2-5], Z.H. Liu made a in-depth knowledge of the genes [6]. However, due to the different purpose of the research, the method and emphasis, product gene doesn't reach a consensus and form a unified concept.

With the development of modern technology, the customer to the product demand is no longer of the single target. People will consider all sorts of different factors and hope each constraint is optimal, that is the multi-objective optimization problems this paper involves. In the modern manufacturing, products in the multi-objective optimization seemed outstanding.

Genetic algorithm, as a biological modeling intelligent optimization algorithm, is widely used in all kinds of artificial intelligence optimization problems. Product genetic engineering has product gene separation, replaced, combination and mutation technology, corresponding to the genetic algorithm coding, selection, crossover and mutation. While the standard genetic algorithm used binary coding with big Hanming distance, it will reduce the efficiency and precision of the calculation of genetic algorithm and will have weak local search ability. It's not conducive to find optimal solutions. Matrix code can very good at expressing combination problems. It has been applied to solve the multi-objective optimization problems with more objective function. In this paper, we use genetic algorithm based on matrix code to solve the multi-objective optimization problem of products genes.

This paper is organized as follows: in Section 1, we sketch out the related problems of the product gene. Multi-objective optimization model is put forward in Section 2. In section 3, we propose the MGA for solving the multi-objective problems. In Section 4, an example is given. Section 5 concludes this paper by making some remarks. 


\section{Overview of product gene}

The origin of the product gene. In order to adapt to the rapid development of information technology, manufacturing technology, modern management technology and system technology, many enterprises focused on the collaboration of each departments and sharing of product information in the product whole life-circle, so as to shorten the develop circle and cost of product, to improve the quality and product, and to enhance the enterprise market competitiveness [7]. The product gene emerges on these occasions. The product gene aims at information share among application systems through expressing the basic information status and logical data model of some area, organization or system.

The expression of product information gene. Through imitating the deoxyribonucleic acid (DNA) in biology gene engineering, each characteristic structure is identified in the gene form by building product information model. In manufacturing industry, each structure is corresponded to some attributes, such as cost, appearance, weight. In this paper, we select matrix as the gene expression form. We construct matrix $A=\left[S_{1}, S_{2}, S_{3} \ldots S_{n}\right]$ with $m$ rows and $n$ columns, with $m$ rows vector $\mathrm{Si}$. In vector $\mathrm{Si}$, each column is corresponded to the $\mathrm{m}$ kinds of attributes of structure $\mathrm{i}$, such as cost, appearance, and weight. In matrix A, the first row indicates $\mathrm{n}$ kinds of structure. From the second row to the last, they map the attributes of structure $\mathrm{S}_{\mathrm{i}}$. For example, in matrix $\mathrm{A}$,

$$
A=\left[\begin{array}{cccc}
a_{11} & a_{12} & \ldots & a_{1 n} \\
a_{21} & a_{22} & \ldots & a_{2 n} \\
\vdots & \vdots & \vdots & \vdots \\
a_{m 1} & a_{m 2} & \ldots & a_{m n}
\end{array}\right]
$$

$a_{1 i}(i=1,2,3 \ldots \ldots n)$ expresses $n$ kinds of structures, $a_{2 i}(i=1,2,3 \ldots \ldots n)$ means the cost of $n$ kinds of structure while $a_{3 i}(i=1,2,3 \ldots . . n)$ identifies the appearances. Similarly, $a_{i j}$ identifies the ith attribute of structure $\mathrm{j}$. In this paper, all elements in matrix A are defined in float number.

Analysis of customers' requirements. People will evaluate the product value before making the decision to purchase it. In this paper, we choose the bicycle as the example. The customer expected the bicycle to be safe, speed controlled, comfortable with moderate cost and parking steadily. We analyze the customers' requirements and list the functionality to be implemented as follows:

$$
\text { Ride }\left\{\begin{array}{c}
\text { direction control } \\
\text { comfortablity } \\
\text { security } \\
\text { speed } \\
\text { parking steadily }
\end{array}\right.
$$

The main functionality of bike is to reduce the overworking of foot. The main functionality can be divided into two kinds, stationary functionality and dynamic functionality. For bicycle, the direction and speed are demanded to be controlled easily and to be comfortable and safe, including parking steadily. Also people to prefer highly praised commodities.

\section{The MOO model of product genetic engineering}

Multi-objective optimization. Multi-objective optimization problem is short for MOP (multi-objective problem). Decision variables form vector in the domain of definition to make a group of conflicting function values achieve minimal at the same time [8]. The mathematical model describes as follows: 


$$
\begin{aligned}
& \min F(x)=\left(F_{1}(x), F_{2}(x), \ldots F_{n}(x)\right)^{T} \\
& \text { s.t. } \quad g_{i}(x)<0 \quad i=1,2, \ldots p \\
& \quad h_{j}(x)=0 \quad j=1,2, \ldots q \\
& \quad x_{L} \leq x \leq x_{U} \quad x=\left(x_{1}, x_{2}, \ldots x_{m}\right)^{T}
\end{aligned}
$$

E.g. (1) $\mathrm{F}(\mathrm{x}), \mathrm{g}(\mathrm{x})$ and $\mathrm{h}(\mathrm{x})$ is the objective function and inequality constraints; Parameter $\mathrm{n}, \mathrm{p}, \mathrm{q}$ is the number of functions; $\mathrm{x}$ is the decision vector.

Adaptive design from bottom up is used in product genetic engineering. According to the customers' requirements, we divide the function $F$ into $F=\left(f_{1}, f_{2} \ldots f_{n}\right)$, with the corresponding Structure $S=\left(s_{1}, s_{2} \ldots s_{n}\right)$. We have many structure choices $S_{i}=\left(s_{i 1}, s_{i 2} \ldots s_{i 1}\right)$ for implementing one kind of function and each structure has its own cost and evaluation. Here cost and evaluation isn't proportional. The structure has more evaluation doesn't cost more. The customer wants a product that has higher evaluation and function, but cost close to how he can afford.

Matrix can express the combination of multi-objective problems better and look more direct. So we use matrix to show our question. In this paper, we use bicycle as an example. We only take cost, function and evaluation into consideration. First, we have function matrix. That is a matrix between function and structure as following:

$$
\left[\begin{array}{cccc}
\mathrm{B}_{1} & 0 & \cdots & 0 \\
0 & \mathrm{~B}_{2} & \cdots & 0 \\
\vdots & \vdots & \ddots & \vdots \\
0 & 0 & \cdots & \mathrm{B}_{\mathrm{n}}
\end{array}\right]
$$

We get a $n * n$ matrix, row stands for different function of size $n$. Column is the corresponding structure. $B_{i}$ is partitioned matrix and $B_{i}=\left(b_{i i 1}, b_{i i 2} \ldots b_{i i 1}\right), b_{i i l}$ stands for the lth structure of the ith function. Because $b_{\text {iil }}$ just a description, we use a constant to replace.

Then is the attribute matrix of structure. In this paper, we just take cost and evaluation into consideration. $A=\left(A_{1}, A_{2} \ldots A_{n}\right)$ is consist of partitioned matrix . The element in $A_{i}$ like $a_{\text {iil }}$ is given by a unified standard, $\mathrm{c}_{\mathrm{iil}}$ and $\mathrm{e}_{\mathrm{iil}}$ is given by market investigation.

$$
A_{i}=\left[\begin{array}{cccc}
\mathrm{a}_{\mathrm{ii}_{1}} & \mathrm{a}_{\mathrm{ii}_{2}} & \cdots & \mathrm{a}_{\mathrm{ii}_{1}} \\
\mathrm{c}_{\mathrm{ii}_{1}} & \mathrm{c}_{\mathrm{ii}_{2}} & \cdots & \mathrm{c}_{\mathrm{ii}_{1}} \\
\mathrm{e}_{\mathrm{ii}_{1}} & \mathrm{e}_{\mathrm{ii}_{2}} & \cdots & \mathrm{e}_{\mathrm{ii}_{1}}
\end{array}\right] .
$$

The Multi-objective optimization model. The modern manufacturing's goal is to produce a set of productions that not only satisfy customer but also businessman. In this paper, we will find out the best structure group that has higher evaluation and function, but cost close to how he can afford. Objective function as following:

$$
\left\{\begin{array}{rr}
\max & \\
\mathrm{s}_{11_{1}}, \mathrm{~s}_{22_{1}}, \ldots \mathrm{s}_{\mathrm{nn}_{1}} & \left(\sum_{\mathrm{i}=1}^{\mathrm{n}} \mathrm{b}_{\mathrm{ii}_{1}}\right) \\
\max & \\
\mathrm{s}_{11_{1}}, \mathrm{~s}_{22_{1}}, \ldots \mathrm{s}_{\mathrm{nn}_{1}} & \left(\sum_{\mathrm{i}=1}^{\mathrm{n}} \mathrm{e}_{\mathrm{ii}_{1}}\right) \\
\mathrm{min}_{\mathrm{s}_{11_{1}}, \mathrm{~s}_{22_{1}}, \ldots . \mathrm{s}_{\mathrm{nn}_{1}} \mid}\left|\sum_{\mathrm{i}=1}^{\mathrm{n}} \mathrm{c}_{\mathrm{ii}_{1}}-\mathrm{c}\right|
\end{array}\right.
$$


E.g. (2) $b_{i i l}, e_{i i l}$ and $c_{i i l}$ is non-zero constant, $c$ is the cost that costumer can afford. We adopt the weight coefficient to transform multi-objective problem into a single goal. Then we have E.g. (3) $\mathrm{b}_{\mathrm{iil}}, \mathrm{e}_{\mathrm{iil}}$ and $\mathrm{c}_{\mathrm{iil}}$ is non-zero constant, $\alpha, \beta$ and $\gamma$ is different weight coefficient value [9]. As following:

$$
\begin{aligned}
& \max \\
& \mathrm{s}_{11_{1}}, \mathrm{~s}_{22_{1}}, \ldots \mathrm{s}_{\mathrm{nn}_{1}} \quad\left(\alpha \sum_{\mathrm{i}=1}^{\mathrm{n}} \mathrm{b}_{\mathrm{ii}_{1}}+\beta \sum_{\mathrm{i}=1}^{\mathrm{n}} \mathrm{e}_{\mathrm{ii}_{1}}-\gamma\left|\sum_{\mathrm{i}=1}^{\mathrm{n}} \mathrm{c}_{\mathrm{ii}_{1}}-\mathrm{c}\right|\right)
\end{aligned}
$$

\section{Modified genetic algorithm}

For multi-objective combinatorial optimization problem of product genetic engineering, we have some changes for the standard genetic algorithm [9] as following:

(1) Matrix encoding. Because the standard genetic algorithm use binary coding method, but binary string doesn't offer much relevant information of the actual problems, and the matrix code can express the various feature attribute very clear.

(2) Column crossover. Different from the single point cross or the multi-point crossover, column cross can only exchange the whole list, or the information will be upset. Because each column represents all attribute.

(3) Adaptive mutation. The corresponding property values will adaptability to change when a structure change.

\section{Application Case}

Problem Description. In this paper, we choose bicycle as an application case. The functionality of bicycle is divided as mentioned above. The main functionality is to replace walking on foot. The sub functionality includes direction f1, speed f2, safety f3, comfort, and parking steadily, and the corresponding is handlebars, wheel, brake, seat and supporting structure. For the listed kind of structures, the choices are listed in table 1.

\begin{tabular}{|c|c|c|c|c|}
\hline handlebars & wheels & brakes & seat & support \\
\hline straight & wide tire, big wheel & $\begin{array}{l}\text { double } \\
\text { brakes }\end{array}$ & leather seat with spring & $\begin{array}{l}\text { one-sided } \\
\text { support }\end{array}$ \\
\hline side bend & Wide tire, small wheel & front brake & $\begin{array}{l}\text { Leather seat without } \\
\text { spring }\end{array}$ & \multirow[t]{3}{*}{$\begin{array}{l}\text { two-sided } \\
\text { support }\end{array}$} \\
\hline \multirow{2}{*}{$\begin{array}{l}\text { decurved } \\
\text { handlebars }\end{array}$} & narrow tire, big wheel & \multirow[t]{2}{*}{ rear brake } & Woody seat with spring & \\
\hline & narrow tire, small wheel & & $\begin{array}{l}\text { Woody seat without } \\
\text { spring }\end{array}$ & \\
\hline
\end{tabular}

Table 1 Sub Structure for bicycle

To be simple in matrix coding, the structure choice is indexed by $1,2,3,4$, and the evaluation degree is classified by $1,2,3,4,5$, cost with $1 \sim 10$, functionality degree in $1 \sim 3$. We defined prior structure in bigger number. Suppose the customer's requirements are direction controlled flexibly, medium speed, precise brake, parking steady with expected cost 26 . We consider the handlebars, wheel, brakes and support structure in detail owing to the seat being produced uniformly. Here we list the structure matrixes of handlebars and wheel. As following:

$$
\mathrm{s}_{1}=\left[\begin{array}{llll} 
& \mathrm{s}_{11} & \mathrm{~s}_{12} & \mathrm{~s}_{13} \\
\mathrm{~S} & 1 & 2 & 3 \\
\mathrm{C} & 5 & 6 & 7 \\
\mathrm{E} & 4 & 5 & 4 \\
\mathrm{~F} & 1 & 3 & 2
\end{array}\right] \quad \mathrm{s}_{2}=\left[\begin{array}{lllll} 
& \mathrm{s}_{21} & \mathrm{~S}_{22} & \mathrm{~s}_{23} & \mathrm{~s}_{24} \\
\mathrm{~S} & 1 & 2 & 3 & 4 \\
\mathrm{C} & 9 & 7 & 8 & 5 \\
\mathrm{E} & 3 & 4 & 5 & 4 \\
\mathrm{~F} & 2.5 & 2 & 3 & 2
\end{array}\right]
$$




\section{Modified genetic algorithm for multi-objective optimization problem.}

(1) Encoding and initialization. Suppose we choose the third handlebar, the fourth wheel, the

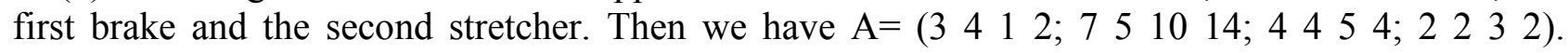
According to such rules, we can random generate 50 initial population.

(2) Evaluation of the fitness functions. We use the value of Eq. (3) as evaluation. The greater the value is, the optimal the structure combination.

(3) Crossover and mutation. Modified genetic algorithm adopts matrix encoding, each column stands for a kind of structure and attribute. So we use single column crossover. In the same way, the attribute value must change to match for its structure when a structure has changed. We have the crossover probability $\mathrm{P}_{\mathrm{c}}=0.7$ and mutation probability $\mathrm{P}_{\mathrm{m}}=0.1$.

Set parameter $M=20, T=100$. We have the following figure:

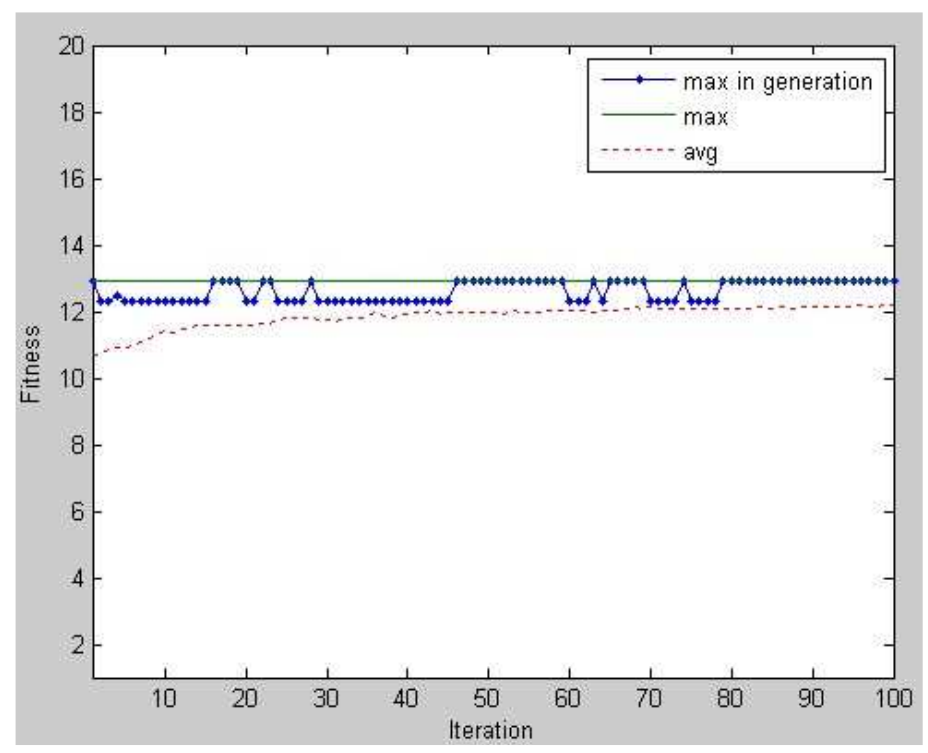

Fig.1. Maximum fitness, average fitness and maximum fitness in each generation

Fig.1. shows the curve of maximum fitness, average fitness and maximum fitness in each generation. We can know the best fitness is 12.9 . The corresponding structure $A=(2,3,1,2)$ is the same with best theory combination. The average fitness rises slowly at the beginning and finally reaches a plateau. The optimal solution in every generation also tends to the global optimal solution slowly.

\section{Conclusions}

To solve the combination and optimization of multi-objective problems, we propose a genetic algorithm based on matrix coding with columns crossover. The method feasibility is analyzed in theory firstly and experiments results show that genetic algorithm is a good solution to multi-objective optimization problems. It is a new idea in product gene engineering field. As part of our future work, we must affirm our proposed with other MOP. We also want to propose a better algorithm that can solve MOP and avoid precocious local optimum.

\section{Acknowledgements}

This research is funded and supported by the National Natural Science Foundation of China (Grant No.50905133), the Natural Science Foundation of Hubei Province, China (Grant No. 2009CDB255), and the Wuhan Planning Project of Science and Technology (201171034314) 


\section{References}

[1] F.B. Zhu, The fifth generation cangjie input method manual. HongKong, 1999.

[2] S.G. John, K. Vladimir. A genetic engineering extension to genetic algorithms, J. Evolutionary Systems, 2001, 9(1): 71-92.

[3] S.G. John. Extensions to evolutionary systems in design from genetic engineering and developmental biology, C. Proceedings 1999 Congress on Evolutionary Computation-CEC99, IEEE, Piscataway, New Jersey, 1999: 474-479.

[4] S.G. John. Developments in computer aided design, C. In H. Li, Q. Shen, D. Scott and P. Love(eds), INCI T E 2000, HKPU Press, Kowloon, Hong Kong, 2000:16-24.

[5] S.G. John, K. Vladimir. Evolving design genes in space layout problems, J. Artificial Intelligence in Engineering. 1998, 12 (3): 163-176.

[6] Z.H. Liu, Knowledge gene explore, J. Intelligence theory and practice. 1998, 21(1): 62-64.

[7] R. Oetter, C.D. Barry, L.A. Decan, P.F. Sorensen, Integrating Manufacturing and Life Cycle Information into the Product Model, J. Journal of Ship Production, 2004, 20:221-231.

[8] A. Mesac, A. Ismail-Yahaya, Multiobjective robust design using physical programming, J. Structural and Multidisciplinary Optimization, 2002, 23(5): 357-371.

[9] M. Zhou, S.D. Sun. The theory and application of genetic algorithm. Beijing, 1999. 